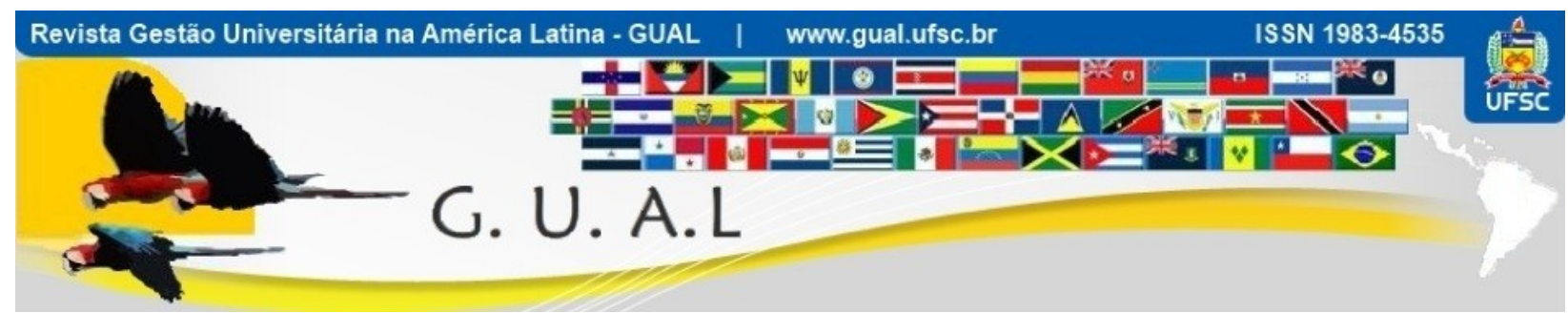

DOI: http://dx.doi.org/10.5007/1983-4535.2013v6n1p253

\title{
CIDADANIA E PRODUÇÃO UNIVERSITÁRIA: O PERFIL DOS DIRIGENTES E A INSTITUCIONALIZAÇÃO DE PRÁTICAS DEMOCRÁTICAS
}

\section{UNIVERSITY CITIZENSHIP AND UNIVERSITY PRODUCTION UNIVERSITY'S BOARD OF DIRECTOR'S PROFILE AND DEMOCRATIC ADMINISTRATION PRACTICES}

Lenin Santos Pires, Doutor Universidade Federal Fluminense - UFF leninpires@yahoo.com.br

Roberto Kant de Lima, Doutor Universidade Federal Fluminense - UFF rkantbr@gmail.com

Recebido em 10/novembro/2012

Aprovado em 28/dezembro/2012

Sistema de Avaliação: Double Blind Review

Esta obra está sob uma Licença Creative Commons Atribuição-Uso. 


\title{
RESUMO
}

No presente artigo os autores propõem uma reflexão, a partir de suas pesquisas sobre processos administração institucional de conflitos, e longa vivencia no ambiente universitário, sobre as práticas universitárias vigentes. Os autores focalizam o sistema de crenças que opõem os saberes profissionais docentes e técnico-administrativos. Este responsável pela estratificação e hierarquização das posições sociais dos sujeitos, a partir de seu pertencimento a uma ou outra categoria profissional, em detrimento dos conhecimentos fundamentais para o funcionamento administrativo das instituições. Neste panorama, ganham relevo os grupos políticos que se organizam através de malhas de relações, envolvendo funcionários e professores, sempre numa relação hierárquica que não se fundamenta no conhecimento profissional especificamente. Grupos que disputam e exercem significativo poder por sobre as estruturas institucionais prescritas. O texto estimula o exercício de por sob descrição tais processos, em prol da necessidade do amadurecimento do debate acerca da eficiência e efetividade dos processos de gestão dos assuntos universitários e acadêmicos. O artigo coloca em discussão a natureza da profissionalização requerida para os dirigentes universitários, em prol da democratização e universalização dos recursos institucionais desenvolvidos em torno dos esforços acadêmicos de ensino, pesquisa e extensão.

Palavras-chave: Gestão universitária. Desigualdade. Hierarquia. Democracia. Qualificação

\begin{abstract}
Based on research on institutional processes of conflicts administration and long experience on university routine, the article focus on the opposition between university teachers' and university staff's practical professional knowledge, considered as responsible for an undesirable hierarchy on their social positions at the University professional ranks. This hierarchy is also disputed by political groups which are competing for offices at university elections. It is proposed a reflection on these processes in order to make progress towards a more efficient and effective university administration both at the administrative and the academic levels. It is also discussed which criteria should be required to build profiles to be filled up by members of the university Board of Directors, in an effort towards democratization and univesrsalization of the institutional resources necessary to the proper development of the university commitments on teaching, research and extension.
\end{abstract}

Keywords: University management. Inequality. Hierarchy. Democracy. Qualification. 


\section{INTRODUÇÃO}

A promoção de práticas democráticas plenas, em prol da universalização de seus recursos para o público, é um desafio permanente para a Universidade Pública brasileira, na medida em que esta ocupa lugar de alta relevância como formadora das elites brasileiras. A conjugação de esforços para interação com tal demanda parece ter possibilitado, nos últimos anos, significativa ampliação do acesso ao ensino universitário de graduação para distintos segmentos sociais. Igualmente, tem sido possível observar um crescente volume de políticas públicas para incrementar a iniciação científica, atividades de extensão, como também a pósgraduação. Estas têm estimulado a realização de vocações acadêmicas ou mesmo mitigado o fenômeno recorrente da evasão de estudantes. No entanto, para que a democratização da Universidade pública alcance níveis mais significativos, nos parece necessário uma discussão sobre sua reestruturação no nível interno.

Antes de esgrimir argumentos sobre eventuais processos de escolha de dirigentes, ou discorrermos sobre os conteúdos ideais de possíveis programas políticos para a Universidade, entre outros assuntos, nos parece que há uma discussão prévia a ser feita. Este artigo, assim, partirá da necessidade do amadurecimento do debate acerca da eficiência e efetividade dos processos de gestão dos assuntos universitários e acadêmicos. Buscaremos colocar em discussão a natureza da profissionalização requerida para os dirigentes universitários, em prol da democratização e universalização dos recursos institucionais desenvolvidos em torno dos esforços acadêmicos de ensino, pesquisa e extensão.

Nas próximas linhas, assim, tomaremos este exercício tendo como referencial as etnografias de processos de administração institucional de conflitos em diferentes sociedades; tanto as realizadas por pesquisadores do INCT-InEAC ${ }^{1}$, ao qual pertencemos, como aquelas presentes em trabalhos de outros cientistas sociais. Alguns desses estudos empíricos apontam para diferentes concepções e valores em torno da concepção da categoria público, em distintas tradições jurídico-políticas ${ }^{2}$. Por exemplo, a categoria público pode estar associada à detenção de um vínculo com uma determinada coletividade (public), com interesses gerais e abstratos de caráter republicano (publique, como em République) e a estatal (como em público, em português) (Kant de Lima, 2008a: 166). Essas diferenças são reveladoras das formas distintas

\footnotetext{
1 O Instituto de Estudos Comparados em Administração Institucional de Conflitos é um Instituto Nacional de Ciência e Tecnologia sediado na UFF e que congrega pesquisadores de diferentes instituições universitárias do Brasil e do exterior. Para saber mais sobre o tema acessar www.uff.br/ineac.

2 Ver, por exemplo, DaMatta, 1985 e 1997; Cardoso de Oliveira, 2002; Carvalho, 2001
} 
de se representar as articulações entre as esferas (o mundo das regras) e espaços (o mundo das práticas) públicos (Cardoso de Oliveira, 2002: 22) e, em consequência, as diferentes lógicas presentes nas práticas dos funcionários públicos em uma sociedade. No Brasil, como veremos, a indagação sobre tais significados podem nos levar a nos perguntar se, afinal, o funcionalismo na universidade se caracteriza por servir ao público ou ao Estado (Lobão, 1998). E ainda interpretar possíveis razões de nossas configurações, em virtude da persistência de uma predisposição para a hierarquização e desigualação dos sujeitos no espaço público.

\section{ATIVIDADES PARA A GESTÃO UNIVERSITÁRIA: MEIOS E FINS}

Indo diretamente ao ponto, no âmbito das universidades federais observa-se a convivência de dois conjuntos de fazeres - e saberes - que são concebidos como separados, em valor e importância. Estas representações, intervindo sobre o imaginário coletivo, concebem atividades-fins que deveriam se realizar em conexão com as chamadas atividadesmeio. Entretanto, essa suposta articulação cria uma ambiguidade e uma tensão que ora opõe o conjunto de profissionais técnico-administrativos ao segmento docente, ora aproxima-os de forma hierarquizada, transformando os primeiros em subalternos do segundo. Entre ambos, evidentemente, estão os discentes que, ora constituem o público - ou a platéia - nos discursos políticos que podem ser acionados pelos dois primeiros segmentos, ora constituem parte da "comunidade universitária", tendo o poder de falar e deliberar em conjunto com os outros dois, no âmbito dos fóruns institucionais existentes.

Pode-se dizer, por outro lado, que nos momentos de greve nas universidades- onde no mais das vezes o governo federal é apontado como o principal adversário, embora muitas vezes não seja o único - tais polarizações tendem a recrudescer. Há dimensões em tais processos que podem ser exploradas, de acordo com certos interesses, como uma pretensa "luta de classes". Como se entre ambos segmentos assalariados se erigissem meios de produção que, ao serem apropriados por uns, promovem a alienação de outros. Não por acaso, historicamente, as reivindicações dos movimentos organizados dos técnicos-administrativos em educação, ao tempo que reclamam melhorias salariais e das condições de trabalho, também cobram maior simetria nas relações internas.

Tais cobranças se traduzem, muitas vezes, na reivindicação de estatuintes, ou seja, processos legislativos internos que venham a reformular as normas de convivência nas 
universidades, removendo os ranços autoritários nos estatutos pré-existentes. Ou ainda no estabelecimento de regras eleitorais fundamentadas, no mínimo, no voto paritário ${ }^{3}$ e, sobretudo, na maior participação de funcionários e estudantes nas instâncias de decisão ${ }^{4}$. No entanto, em que pese a disposição dos técnico-administrativos organizados em se fazerem reconhecer como sujeitos, persiste a noção que suas atividades, comparadas com a dos docentes, são dotadas de menor valoração.

Certamente, esta é uma questão fundamental, pois envolve não somente uma discussão da natureza da hierarquia universitária, como também sobre a natureza do trabalho universitário e do valor monetário extremamente desigual atribuído pelo mercado a diferentes tipos de trabalho em nosso país, expresso de forma explícita nas discussões sobre os valores monetários do salário mínimo. Quais as razões da persistência dessa noção?

Não se pode esperar uma resposta única e definitiva para esta indagação. No entanto, se pode argumentar que a recorrência de tal preconceito encontra certo fundamento nos conceitos e alegorias imaginados na formação da nação brasileira. Neste sentido, é interessante recorrer a um fragmento da obra de Eça de Queiroz, resgatado oportunamente por Fonseca (1996). Na passagem do conto o autor veicula, através de um de seus personagens, uma noção muito forte sobre o papel do conhecimento na sociedade brasileira, uma década antes da República.

\footnotetext{
"A primeira vantagem da Universidade, como instituição social, é a separação que se forma naturalmente entre estudantes e futricas (...). Assim, o estudante fica para sempre penetrado dessa grande idéia social: que há duas classes - uma que sabe, outra que produz. A primeira, naturalmente, sendo o cérebro, governa; a segunda, sendo a mão, opera, e veste, calça, nutre e paga a primeira" (Queiroz apud Fonseca, 1996: 23)
}

Futrica, originalmente, era como os estudantes da Universidade de Coimbra chamavam aos naturais da cidade, os quais não eram estudantes. A mesma Universidade de Coimbra que, diga-se de passagem, era o centro formador das elites brasileiras no período colonial e, sobretudo, quando o país foi sede do império colonial português. Este, como se sabe, diferentemente de seus congêneres europeus, não permitia a instituição de universidades

\footnotetext{
3 Forma de ponderação dos votos de cada segmento universitário que faz com que os votos de docentes, técnico-administrativos e estudantes sejam contados enquanto equivalentes, considerando todo o universo de cada um dos segmentos. Seria o equivalente a dizer, de uma forma demasiadamente simplista, que em uma universidade que tenha, respectivamente, 100 professores, 1000 funcionários e 10.000 alunos, o voto de um professor equivale a de 10 funcionários e 100 alunos.

4 Ao longo das duas últimas décadas, como parte das táticas de luta, representações de técnico-administrativos e estudantes, de norte a sul do país, estreitaram laços, construindo pautas de reivindicação em comum, em vários momentos de luta política.
} 
fora da metrópole, datando do século XIX a fundação das primeiras Faculdades em nosso país.

Daí que a categoria futrica foi também empregada, no meio escolar brasileiro, para aqueles que não eram estudantes ou que, incipientemente, tinham apenas dois anos de preparatório. Com o passar do tempo, o vocábulo adquiriu conjugação de verbo, sendo a prática do futricar o mesmo que semear intrigas, geralmente com veiculação de fofocas ${ }^{5}$. Claro está aí a oposição entre verdade e mentira. Uma pertencente aos domínios dos “doutos"; a outra, claramente vinculada à ignorância plebéia. Daí que o futrica, diferentemente do bacharel, não caminha nos trilhos da civilização. Sua racionalidade é outra, para não dizer retrógrada. E é por isso que "o bacharel, tendo a consciência de sua superioridade intelectual, da autoridade que ela lhe confere, dispõe do mundo; ao futrica resta produzir, pagar para que o bacharel possa viver" (Queiroz apud Fonseca, op. cit: 23).

\footnotetext{
"Como pode realmente o homem que todo o dia trabalhou no seu tear, e à noite, depois do caldo de couves, dormiu do sono brutal da fadiga física, participar do governo da coisa pública - como esse outro homem que conhece as línguas, tem os princípios da introdução aos três reinos, estudou o direito romano, se penetrou do direito canônico, leu os poetas do século, discutiu as leis no Parlamento, fez administração nas secretarias?" (Queiroz apud Fonseca, op. cit: 23).
}

Em nosso país, no entanto, um outro fator somou-se a este viés histórico da formação da instituição universitária: sabemos que o Brasil foi o último país que aboliu a escravatura, no final do século XIX, concomitantemente com um movimento que mudou o regime político imperial em republicano. Ora, se nos dermos conta de que durante a própria escravidão, os escravos libertos urbanos adquiriam escravos para que se lhes ganhassem o sustento, pode-se inferir o quão profundamente está entranhada a idéia da desigualação pelo mercado de trabalho.

Articula-se aqui, então, uma visão hierárquica da sociedade, que opera com o pressuposto de uma desigualdade de poder produzida e reproduzida por uma desigualdade de acesso ao conhecimento, atribuindo ao trabalho intelectual um valor desigualado de outros tipos de trabalho, a uma visão que desiguala e desvaloriza certos tipos de trabalho, associado ao trabalho de escravos e atribuídos àquelas "peças" que não possuíam identidade civil, embora possuíssem responsabilidades na esfera criminal.

5 Daí que se deve estranhar, no sentido antropológico do termo, a natural presença de uma instituição comum aos ambientes universitários: a chamada Rádio Corredor,
responsável pela propagação de supostos boatos e fofocas, as quais, inclusive, surtem efeitos, ainda que temporários, na condução dos assuntos administrativos universitários. 
Pensamos que tais noções, por mais anacrônicas e rançosas que possam parecer, conjugam-se a outros fatores, especialmente àqueles relacionados com a apropriação particularizada dos bens públicos, para esclarecer algumas das razões que dificultam a constituição de uma estratificação igualitária em nossas instituições públicas, em especial nesse "templo do saber" que é a Universidade.

É mesmo notável para nós, que focalizamos o Direito brasileiro em nossos estudos, a maneira como o viés bacharelesco (particularmente aquele emulado pelas faculdades de direito) estrutura noções, estratifica categorias e informa pensamentos desigualadores. Por que se é notório em vários âmbitos a forte impressão que deixou o Direito nas formas de organização na nossa sociedade, é na universidade que o fosso entre o mundo dos letrados e não-letrados parece não só ter se perpetuado por muito tempo, mas, sobretudo, adquirido contornos abissais.

\section{ALGUMAS REFLEXÕES TEÓRICAS SOBRE O TEMA}

Um conjunto significativo de cientistas sociais brasileiros têm reiteradamente argumentado acerca das dificuldades de adoção, no Brasil, de um discurso que promova a igualdade entre os sujeitos, independente de seus fazeres e saberes ${ }^{6}$. Dificuldade essa que, como vimos argumentando em outros trabalhos, intervém sobre a efetividade dos instrumentos institucionais de administração de conflitos no espaço público ${ }^{7}$. Como se vê nos fragmentos literários acima, estes podem se refletir nos problemas que a sociedade brasileira tem enfrentado na organização democrática dos serviços prestados ao público, particularmente na Universidade.

Em certa medida, essa crença de que há distintas capacidades cognitivas para aquisição de conhecimentos, nas quais se fundamentam e hierarquizam distintos saberes, está estreitamente relacionada à inversão estrutural concedida ao significado atribuído às normas, à lei e aos processos de administração institucional de conflitos. Em sociedades de iguais, normas e regras tendem a ser explícitas e literais, elaboradas por todos e a todos compreensíveis; aplicam-se de maneira uniforme aos diferentes sujeitos em processos que se fundam nas limitações da vida em sociedade e em seus efeitos sobre os iguais compromissos de civilidade que a todos são impostos de maneira uniforme. Já em sociedades de desiguais,

\footnotetext{
6 Ver, por exemplo, Santos, 1985 e Kant de Lima, 1995

7 Ver, por exemplo, Kant de Lima, Eilbaum \& Pires, 2008
} 
normas e regras tendem a ser interpretadas por aqueles que detêm o conhecimento e que as aplicam desigualmente, sobre os segmentos desiguais da população, para fazer justiça. $\mathrm{O}$ conhecimento, assim fica associado necessariamente ao poder e o poder é visto como resultado da posse do conhecimento, sempre apropriado de forma particularizada.

Assim, processos de administração de conflitos em nossa sociedade tornam-se instrumentos de apropriação e manutenção de poder. Em lugar de representar mecanismos de proteção de todos, como ocorre nas sociedades de tradição democrática mais consolidada, acabam a lei e o processo de sua aplicação por serem identificados como um mecanismo de opressão, aplicados por aqueles que sabem mais, sobre aqueles que sabem menos. A consequência mais imediata disso é que, enquanto os processos de internalização de limites e de contenção no espaço público tornam-se os principais mecanismos disciplinares de regulação dos comportamentos sociais nas sociedades igualitárias, nas sociedades de desiguais, pelo contrário, a repressão se torna a mais efetiva forma de administração institucional de conflitos: não se pode facilmente convencer a sujeitos que têm direitos desiguais que devem estar submetidos a deveres iguais.

O conhecimento, consequentemente, e por analogia, é considerado um valor a ser apropriado particularizadamente. Sua detenção provoca distinção e, por isso, separa o douto do pé rapado, sendo o segundo, potencialmente, um serviçal para o primeiro.

Como sugere nosso exemplo, os períodos anteriores à nossa República tiveram seus ambientes sociais definidos por uma representação do conhecimento enquanto um domínio de poucos, de conteúdo hermético e dotado da faculdade de submeter aqueles que eram, por definição, alienados do mesmo. É importante frisar que tais construções circulavam nos meios intelectuais do regime monárquico, cujos expoentes que chegavam às estruturas de poder advinham das Escolas de Direito existentes: as de Pernambuco (Olinda e depois Recife) e de São Paulo. Como conseqüência desse exercício, a Lei, expressão do conhecimento, era e é vista como algo externo à sociedade, propriedade e instrumental daquele que exerce o poder (Kant de Lima, 2000: 110). No entanto, sabe-se que inúmeras transformações afetaram a sociedade brasileira contemporânea e, em consequência, suas tradições político-jurídicas.

Mas, como já apontou DaMatta, nosso sistema de crenças burocrático-jurídico-político permite ambiguidades e a convivência de paradoxos, delas decorrendo que a sociedade brasileira, juridicamente, enfatiza, tanto na esfera (lugar das regras) como no espaço (lugar das .práticas) públicos, alternada e alternativamente dois modelos: um individualista e 
igualitário, como se fôssemos uma república de cidadãos diferentes, mas com iguais direitos; e um outro holista e hierárquico, em que nos representamos como uma sociedade aristocrática, composta de segmentos desiguais, a que correspondem, necessariamente, direitos e deveres desiguais. O modelo a ser acionado em público vai depender das circunstâncias e do contexto argumentativo que se deseja estabelecer, de maneira puramente instrumental.

Logicamente, muitas décadas se passaram desde que Eça de Queiroz registrou na fala de um de seus personagens as imagens e ações de um Brasil às vésperas da chamada República. Mudanças significativas puderam ser verificadas desde então, com a introdução de novos sujeitos sociais veiculando, de acordo com suas possibilidades, seus interesses. Entre estes últimos, porém, alguns tendem a ser mais legítimos que outros, não só em função da sua situação no mercado, mas também em função da sua posição social. Quanto mais, ou menos, próximos das estruturas de poder, estes mesmos interesses podem ser objeto da fórmula que muitos atribuem a Getúlio Vargas, nos idos da década de 30: “Aos amigos tudo, aos inimigos os rigores da Lei”.

É fato que a sociedade brasileira se define jurídica e explicitamente como estruturada em um regime constitucional republicano e democrático. A Constituição Federal de 1988 chamada de cidadã - reafirmou essa opção, consagrando em seu artigo $5^{\circ}$ o princípio de que todos são iguais perante a lei. Assim, em primeira análise, podemos identificá-la com o modelo igualitário. Mas há entre nós o adágio popular, que complementa a previsão constitucional supracitada: "só que alguns são mais iguais que outros". Esse tem suporte em um conhecimento social disseminado acerca da desigualdade que marca as relações sociais no espaço público, não apenas em função da quantidade de capital que desiguala os cidadãos em um sistema de mercado, mas em função de outros indicadores. Expressão disso é que nosso sistema judicial institui continuamente privilégios que sistematicamente desigualam o tratamento dos conflitos que lhe são apresentados para administrar, em função da categoria social dos envolvidos, administrando-os com ênfases inquisitoriais e repressivas, próprias do modelo que atuou no antigo regime ${ }^{8}$. Quando confrontado aos princípios constitucionais acusatórios e consensuais, este modelo produz ruídos dissonantes.

\footnotetext{
8 Célebre, neste sentido, é a essência do texto "Oração aos moços" pronunciado por Rui Barbosa, no qual ensina aos alunos da Faculdade de Direito do Largo de São Francisco, em março de 1921: "A regra da igualdade não consiste senão em aquinhoar desigualmente aos desiguais, na medida em que se desigualam. Nesta desigualdade social, proporcionada à desigualdade natural, é que se acha a verdadeira lei da igualdade. O mais são desvarios da inveja, do orgulho, ou da loucura. Tratar com desigualdade a iguais, ou a desiguais com igualdade, seria desigualdade flagrante, e não igualdade real. Os apetites humanos conceberam inverter a norma universal da criação,
} 
O sistema jurídico entre nós está baseado na dogmática jurídica, como também na hierarquia das normas. A forma como as elites brasileiras constroem as previsões legislativas, no entanto, configura-se com fundamento em um sistema para a administração institucional de conflitos entre os desiguais. Tais processos legislativos sustentam, explicitamente, condições desiguais para seu desenvolvimento, em função das posições sociais e funcionais das pessoas que deles participam. Por sua vez, se desdobram através da lógica do contraditório, cuja função é opor, indefinidamente, posições contrárias. Segundo tal lógica, o problema deve ser resolvido, quando argüido, validando, assim, automaticamente, aquelas normas situadas nos níveis mais altos da hierarquia. E deve ser feito por uma autoridade externa às partes em conflito. Uma autoridade que deverá decretar qual a verdade sobre uma disputa, independente até dos interesses dos contendores. Afinal, quem está no topo da hierarquia sabe mais, inclusive (ou principalmente) o que é melhor ou pior para os outros. Daí a sentença, disseminada no senso comum, "manda quem pode, obedece quem tem juízo".

Esta forma de administrar institucionalmente conflitos expande-se pelo sistema burocrático-administrativo brasileiro, dificultando, sobremaneira, tanto a assunção de mecanismos de construção de regras consensuais reguladoras das atividades da administração pública, como a implantação de processos fundados na negociação explícita de interesses dos envolvidos. $\mathrm{O}$ interesse público, frequentemente interpretado de maneira peculiar e particularizada pelos funcionários públicos, parece se opor à negociação dos conflitos e vedar o entendimento entre as partes. Em função disso, as soluções negociadas, em geral, são construídas oficiosamente, muitas vezes obedecendo a um pretenso bom senso, mas às vezes curvando-se a interesses particulares que visam prejudicar, efetivamente, o interesse coletivo. No entanto, como são oficiosas, seu controle é restrito aos casos excepcionais, que não atingem o padrão de sua prática oficiosa.

No Brasil, a inevitável combinação conflituosa entre princípios igualitários e hierárquicos na viabilização de uma sociedade contemporânea, como sugeriu Dumont (2000), tem contornos específicos. As razões desta distinção encontram-se na própria formação histórica do estado e da sociedade brasileiros, marcada por uma cultura político-jurídica que mantém concepções distintas de igualdade jurídica em vigor nos seus estatutos legais e constitucionais (Cardoso de Oliveira, 2002; Teixeira Mendes, 2005). De um lado,

pretendendo, não dar a cada um, na razão do que vale, mas atribuir o mesmo a todos, como se todos se equivalessem (...). Esta blasfêmia contra a razão e a fé, contra a civilização e a humanidade, é a filosofia da miséria, proclamada em nome dos direitos do trabalho; e, executada, não faria senão inaugurar, em vez da supremacia do trabalho, a organização da miséria". 
consideram-se, de acordo com os princípios republicanos, iguais em direitos os cidadãos natural e socialmente diferentes; de outro, consideram-se iguais aos semelhantes, associandose a idéia de diferença à desigualdade de direitos. Mais importante, porém, é que estes paradoxos estão na raiz mesmo das práticas repressivas que, comumente, presidem os processos de administração institucional de conflitos, que obliteram as dimensões da igualdade e da liberdade, dependendo dos estratos sociais a que pertençam os indivíduos. Dessa forma, as políticas públicas podem, muitas vezes, promover a distinção de indivíduos, esterilizando os princípios republicanos que discursivamente instituem o Estado-Nação brasileiro.

\section{E A UNIVERSIDADE NISSO TUDO?}

Ora, o que estamos tratando de fundamentar é a afirmação de que há um sistema de crenças operante na sociedade brasileira que concorre com os ideais igualitários e republicanos. Segundo este, o conhecimento pode ser particularizado por alguns, extravasando o domínio dos conhecimentos privados para produzir efeitos legítimos no espaço público: passa a se constituir, assim, em instrumento de controle e de exercício de poder. Na representação mais simplória, no meio universitário, se pode imaginar que a expressão de tais conflitos se esboça na oposição funcionários X professores. Neste ponto, no entanto, a realidade da vida social nos obriga a focalizar o fenômeno em sua dimensão mais complexa, atentos, portanto, aos paradoxos.

A exemplo do que ocorre em outros contextos no Brasil, o cotidiano profissional universitário não se organiza de forma sistêmica; ou seja, não é recorrente a fixação de uma certa previsibilidade das ocorrências, em função das atribuições institucionais dos cargos e funções. Não por acaso a palavra "processo", dependendo da maneira como é mencionada numa conversa entre servidores, pode gerar receio ou mesmo pânico. Não é incomum um servidor ouvir de um colega, em tom sorrateiro "tem um processo aí para você tomar ciência" e o primeiro, surpreendido, quando não temeroso, perguntar: “que processo?”. É quando se pode perceber de que forma as bases inquisitoriais de formação burocrática da sociedade brasileira podem ser percebidas no cotidiano administrativo das universidades. E como as normas e leis são complementadas pelas interpretações daqueles que sabem. Afinal, tais processos podem, uma vez instruídos, produzir aplicações rigorosas, positivas ou negativas, dependendo de quem ou o que se queira atingir. Ou simplesmente ficarem como "ameaça" 
permanente e latente da posição e função de um funcionário, sempre suscetível de ser ativado (ou "desengavetado") dependendo das circunstâncias.

Da mesma forma, considerando os mecanismos de administração institucional de conflitos, as chamadas Comissões de Sindicância podem ser vistas com temor. Previstas normativamente para apurar fatos relacionados a determinadas ocorrências, garantindo amplo direito de expressão para as partes envolvidas (incluindo o direito à defesa de eventuais acusados de algum desvio funcional), elas podem atuar boa parte do tempo tendo por base o segredo e sigilo das informações, independentemente de incidirem sobre uma trajetória profissional. Dependendo do contexto, sua simples existência pode ser suficiente para atingir reputações, cujas detratações poderão ser ampliadas pela já aludida radio-corredor. Mais ou menos como quando em certas localidades se destrói a reputação de um vizinho pelo simples fato de estar arrolado em um processo judicial. No caso dos técnico-administrativos, muitas vezes, tal reputação poderá ser maculada por bastante tempo em função da possibilidade de, ao não se ajustar às expectativas de uma determinada administração, ser colocado à disposição da área de recursos humanos. Nestas situações passam a integrar o ironicamente denominado banco de talentos.

$\mathrm{Na}$ superfície, talvez, pareça ser o funcionamento da Universidade baseado num encadeamento de ações burocráticas e, portanto, previsível. Entretanto, uma focalização mais detida no fenômeno revelará que ela também opera por meio de malhas de relações, as quais atendem antes ao princípio da confiança entre pessoas que se conhecem e, nestas relações, constroem suas reputações. É baseado nestas reputações que o conhecimento tem maior ou menor validade e não no seu conteúdo per si. Consequentemente, o conhecimento sobre o funcionamento da Universidade não é para todos; ele é empregado de forma particularizada por coletivos de professores, funcionários e, em alguns casos, até de estudantes. Arregimentados em torno de programas e objetivos particulares comuns, nem sempre plenamente explícitos para o público em geral, ou mesmo para todos os membros de seu próprio grupo, em particular. Em função disso, os processos administrativos podem ser diligentemente instruídos, ou não, como também ter mais ou menos celeridade, atingindo seus objetivos com maior eficácia, conforme predispunham os interesses que o fizeram mover-se.

Este funcionamento é o esteio sobre o qual se formam grupos políticos cujo conhecimento acerca das possibilidades (oficiais ou oficiosas) de funcionamento da universidade, das formas de utilização dos recursos disponíveis, das configurações sociais dos 


\section{CIDADANIA E PRODUÇÃO UNIVERSITÁRIA: O PERFIL DOS DIRIGENTES E A INSTITUCIONALIZAÇÃO DE PRÁTICAS DEMOCRÁTICAS DOI: http://dx.doi.org/10.5007/1983-4535.2013v6n1p253}

grupos políticos externos em suas relações com a Universidade, entre vários outros conhecimentos, se configuram em segredos a serem guardados a sete chaves. Segredos estes que, muitas vezes, se instituem com base na já aludida atmosfera inquisitorial que se pode perceber em alguns momentos da vida pública. Assim, há diferentes saberes sobre o que é e como pode ser administrada a Universidade; no entanto, estes saberes não se alinham, formando um elenco de opções uniforme e universalmente disponíveis. São sempre acionados de acordo com um ou outro interesse particular e, neste sentido, têm validade provisória.

Evidentemente, no interior de cada grupamento há também certa hierarquização do que se pode ou não se pode saber. Logo, não há a possibilidade, no interior de um mesmo coletivo de interesses, que um indivíduo, seja ele docente ou não docente, possa compreender com profundidade como se organiza a instituição, partindo do ponto de vista supostamente compartilhado. É claro que está presente a representação de que os docentes devem saber mais ${ }^{9}$. No entanto, como se pode observar por parte deste segmento profissional significativo desconhecimento relação a variados assuntos institucionais, há espaço de manobra suficiente para que determinados técnico-administrativos desenvolvam conhecimentos particularizados. Estes os esgrimem em prol de seus próprios interesses de crescimento no interior do grupo político ao qual estão vinculados e, neste sentido, concorrem para fortalecer o coletivo como um todo. Isso explica, em parte, por que determinados servidores, de norte a sul do país, já foram empossados em cargos de destaque em distintas áreas da administração universitária ${ }^{10}$. Afinal, interessa mais, de acordo com os interesses político-acadêmicos em jogo, que um grupo saiba mais do que outro e, em função desse conhecimento, maneje melhor os recursos disponíveis.

\footnotetext{
9 Dados significativos, acerca do processo de qualificação dos Técnico-Administrativos em Educação e seus impactos nas Instituições Federais de Ensino Superior, por exemplo, nos são revelados pelo estudo de Ana Maria de Almeida Ribeiro, técnica em assuntos educacionais da UFRJ e membro do Grupo de Trabalho sobre Carreira da FASUBRA (Federação dos Sindicatos dos Profissionais em Educação das Universidades Brasileiras)) . Em 2009, segundo ela, de um total de 96.786 TécnicoAdministrativos em Educação lotados nas Instituições Federais de Ensino Superior, 49.928 profissionais possuíam formação universitária, ou seja, 51,6\%. Segundo ainda Ribeiro, as atividades de nível superior nas universidades federais vem crescendo em número e em proporção. Em 2002 as atribuições cujo nível de complexidade demandavam formação superior somavam 21.667, contra um total de 71.587 de atividades de nível médio e auxiliar. Assim, as atividades de nível superior perfaziam $23 \%$. Em 2011, distintamente, as atividades que exigiam nível superior somavam 35.080, contra 80.807 dos outros dois níveis. Ou seja, 30,3\%. Isso nos possibilita pensar que a universidade brasileira, mesmo após seguidas reformas administrativas que propuseram o enxugamento de pessoal, mais que aumentar o quantitativo de pessoal, passou a demandar cada vez mais conhecimento especializado por parte do segmento técnico-administrativo. Apesar disso, mantém-se quase que em um nível estacionário, se compararmos com a conjuntura política do início da década de 1980, o ordenamento administrativo das IFES, que parecem repousar na crença no caráter intrínseco da subalternização desse segmento enquanto atividade-meio àqueles responsáveis pelo desenvolvimento da chamada atividade-fim. (Fonte: RIBEIRO, Ana Maria de Almeida. A Atualidade do Projeto "Universidade para os Trabalhadores". Aula Magna proferida por ocasião dos 25 anos do Curso Pré-Vestibular do Sindicato dos Trabalhadores em Educação da UFRJ, em 27/2/2012. Mimeo).

10 Há casos conhecidos de superintendências de graduação e pós-graduação ocupada por funcionários, em algumas instituições federais de ensino, como também no cargo de Prefeitos. Isso não quer dizer, porém, que tais cargos sejam reservados para funcionários todo o tempo e, mais do que isso, que outros cargos de confiança, em outras áreas da administração central, possam ser destinados para este segmento. Tudo depende, como afirmamos, dos grupos acadêmicos e suas relações políticas.
} 
Logo, ainda que esteja em voga a crença de que está na representação acadêmica o monopólio do saber, há técnico-administrativos que são reconhecidos pelo conhecimento que detém não fundamentalmente por serem funcionários a serviço do público, mas por colocar suas expertises a serviço de um grupo político fortalecido. E é neste ponto que sugerimos alguns questionamentos. Embora seja esta a forma recorrente, pode-se defini-la como a mais democrática na arregimentação de vocações para o exercício de cargos públicos no âmbito universitário? Se nossa interpretação é meramente verossímil, como fazer para promover uma inflexão e, neste sentido, romper com o sistema de crenças que, definindo qualquer forma de conhecimento como um bem a ser particularizado, levou a um processo gradativo de alienação sobre o funcionamento da Universidade por parte de seus próprios membros?

Essa não é uma questão fácil. Para sua apropriada formulação, requer extensa e dedicada pesquisa. Neste sentido, estaremos, doravante, praticando apenas alguns exercícios imaginativos, como também referindo a algumas experiências concretas das quais participamos. O ponto de partida é que a Universidade deve encontrar meios de, ao utilizar mecanismos legais de qualificação e capacitação de seus funcionários - docentes e nãodocentes - lhes dotar de informações que promovam não só o atendimento de demandas legítimas por melhor formação, mas que favoreçam a oferta, para os usuários, de serviços públicos qualitativamente competentes, exercidos de maneira equânime. Que sejam eficientes, ampliando a avaliação positiva e a confiança da sociedade na produção da universidade.

Ora, para isso os conhecimentos para a Gestão Pública não podem ser entendidos como mera aplicação dos conhecimentos adstritos às áreas das ciências sociais aplicadas. É necessário que se constituam conhecimentos a partir da problematização, teórica e metodológica, das relações entre o Estado e a sociedade, em nossa formação política e cultural. Desta forma, a Gestão Pública não deve ser apenas normalizadora, no sentido da adequação de práticas a um modelo pré-determinado de funcionamento acrítico do serviço público; tem que ser também indagadora, focalizada nas necessidades de um diálogo direto com a sociedade e as suas instituições. Significa colocar em dúvida o emprego do termo gerir, como prática decorrente de gerenciar - management, em inglês - que avoca a existência de pressupostos e padrões institucionalizados anteriores às situações concretas. Esta, via de regra, se constitui enquanto um conjunto de conhecimentos válidos para quaisquer universos de problemas. Afinal, recorrer aos sujeitos para quem os serviços públicos são pensados e oferecidos não é uma iniciativa incorporada ao modelo de serviço público instituído. Com 
isso, os servidores se colocam em uma posição de superior desigualdade - como dotados de conhecimentos, diferentemente de supostos futricas da sociedade - o que pode comprometer negativamente a concepção republicana de tais serviços. Nossa aposta é por estimular uma lógica de gestionar, fazer gestões, a partir da lógica da administração - administration - que reconhece a natureza e a dinâmica dos fluxos sociais e a necessidade de negociação das regras, sejam elas as que devem regular o desempenho das práticas funcionais, sejam aquelas que vão regular a administração dos inevitáveis conflitos oriundos da dinâmica social: pois, uma vez tendo curso em uma sociedade igualitária, o serviço público deve incorporar os objetivos da coletividade.

Por isso mesmo desenvolvemos há algum tempo, estimulados pela atual Reitoria da Universidade Federal Fluminense, uma proposta de Curso de Gestão Pública cujo projeto pedagógico não se volta somente para o ensino de conhecidos mecanismos de gestão, a cujo suposto mau funcionamento tem-se atribuído os defeitos do sistema. Não se trata, portanto, de produzir técnicas de gestão onde o conceito de interesse público se traduza como a premissa do Estado hegemonizar o espaço e a esfera públicos, em prol da reprodução de um acionar seletivo e discriminatório do atendimento da sociedade. Antes, primamos por buscar estimular os funcionários que venham a ser participantes de um curso a pensarem em que termos, resguardadas as especificidades culturais brasileiras, se pode promover o interesse público como direito da coletividade a dispor, equanimemente, dos recursos que formam o serviço público. Este último, bem entendido, como um conjunto de práticas para a promoção de uma ordem social e política que enfatize uma perspectiva igualitária.

O que nos parece relevante, portanto, é perceber a natureza diferenciada de nossa tradição política e jurídica. Problematizar as maneiras como o confronto de diferentes interesses, em nossa sociedade, dão lugar a formas particulares de sua administração. Daí deriva o uso da categoria "administração institucional de conflitos" usada por nós em boa parte das ementas e marca registrada de muitos de nossos projetos de caráter institucional. Com isso não utilizamos, propositadamente, as categorias "gestão", ou "resolução", "pacificação" ou "conciliação", todas elas comprometidas, de alguma forma, seja com os valores da uniformização normalizadora do mercado, seja com os valores repressivos da sociedade tradicional.

Em outras palavras, é importante nos propormos a inovar sobre competências já instituídas no mercado como, por exemplo, no Cadastro Nacional de Cursos Superiores de 
Tecnologia. Uma possibilidade é elaborar Cursos de Tecnólogo em Gestão Universitária, na perspectiva de atrair os interesses dos profissionais que trabalham nas IFES, em particular aqueles que ainda não detém nível superior. É possível que estes se sintam estimulados a assumir novas perspectivas para a gestão universitária, calcadas nos valores e princípios acima assinalados. No entanto, opinamos que é fundamental agregar aos respectivos projetos pedagógicos reflexões que vem se responsabilizando por incrementar a produção no campo das Ciências Humanas e Sociais nos últimos 30 anos, mas que ainda não foram incorporadas aos conhecimentos dedicados à administração de recursos no serviço público. A meta, a partir de exemplos como esse, pode ser alterar substantivamente os perfis de profissionais disponíveis na área de gestão administrativa das IFES. Estes vinculados, mormente, às estratégias da burocracia estatal, as quais se distanciam, muitas vezes, da necessária percepção sobre os interesses heterogêneos que formam as demandas e direitos do público assistido.

Muitas vezes, a solução encontrada pelos profissionais do serviço público é a homogeneização das demandas, baseada em critérios que refletem representações e moralidades de grupos sociais específicos, que se tornam dominantes na instituição. Estas, por seu turno, não encontram aceitação ou correspondência nos demais segmentos sociais, dificultando o reconhecimento do serviço público como um recurso da sociedade em geral. Dessa forma, a particularização da esfera e do espaço públicos se torna recorrente, promovendo a deslegitimação dos serviços públicos e seu isolamento do conjunto da sociedade.

Essa desvinculação, como advertiu Cardoso de Oliveira (op.cit), segue uma tradição jurídico-política que, no Brasil, associa a categoria público ao domínio do Estado. O estatal divergindo, como já mencionado, das tradições jurídico-políticas e sociais próprias dos estados democráticos de direito, em que a categoria public e publique, por exemplo, significam, respectivamente, nos Estados Unidos e na França, coletivo e pertencente a todos, republicano. Urge, portanto, instituir no âmbito da universidade pública, gratuita e de qualidade, a produção e reprodução de um campo de conhecimento dedicado à gestão que propicie a transformação da inflexão estatal da gestão pública para o viés do cidadão e da sociedade. Mas como fazê-lo?

Pretendemos, como o presente artigo, dar uma contribuição para eventuais processos de qualificação institucional induzido pelas IFES. Neste sentido, parece-nos de bom tom dirigir a tais políticas públicas parte da responsabilidade nessa mudança de perspectiva. 
Afinal, uma visão corrente sobre os processos educativos define-os como aqueles que constituiriam as condições de produção, explicação e justificação das realidades sociais, políticas, econômicas, culturais e científicas, articuladas e dispostas em estruturas e modelos determinados de sociedade. Tais processos consolidariam a internalização de valores, crenças e representações simbólicas que configurariam as formas de comportamentos relacionais dos sujeitos educandos e desenvolveriam a aquisição de conhecimentos técnicos e apropriação de tecnologias e competências de intervenção. Até o momento, esses direcionamentos dos processos educativos, a formação da consciência social, a definição do caráter identitário e a aquisição de instrumentais necessários à intervenção sociocultural, responderiam à necessidade de manutenção e validação das estruturas e modelos sociais e políticos hegemônicos vigentes. Estimular que os próprios agentes "coloquem sob descrição" tais processos, para problematizá-los e, a partir da participação dos funcionários interessados, redirecioná-los na medida das exigências de promoção de um outro ethos, nos parece um exercício possível.

Por outro lado, a condição de complexa governabilidade social dos fenômenos alocados nas políticas de administração pública e social decorre do reconhecimento de que se trata da interação de múltiplas dimensões no exercício de responsabilidades governamentais, comunitárias, institucionais, culturais e individuais. Estas decorrentes das condições objetivas e subjetivas da sociedade naquilo que gera implicações na viabilização da ordem pública e da democracia. A complexidade sugere caminhos e percursos que se colocam num campo epistêmico compatível com a interdisciplinaridade, que pode ser requerida para instrumentalizá-la e que, esperamos, esteja presente no aludido processo de qualificação. Isto é, além de pensar uma crítica ao modo como o conhecimento científico vem sendo produzido e aplicado para interferir na realidade, é necessário definir com que metodologias é possível criar um conhecimento complexo. Um conhecimento que se torne referencial para as intervenções sócio-culturais, a partir da apropriação do conhecimento por partes, fazendo-o avançar em inter-relações a partir de uma escolha ética que interligue as partes, requalificando e resignificando a atuação e intervenção na realidade.

Uma vez assumida essa perspectiva espera-se, finalmente, em primeiro lugar, a implosão das representações que submetem hierarquicamente os segmentos da comunidade uns aos outros para, num momento que é concomitante ao anterior, integrar simetricamente a instituição, tendo como referência todo o seu público, e não apenas parte dele - o discente - o 
qual volta e meia se busca cooptar dentro das lógicas particularistas de poder. Construindo um plano de simetria, a partir de saberes distintos, os quais se complementam para construir a melhor forma de administrar a Universidade, o cenário no qual se instituem os processos políticos de sucessão das representações institucionais assume outro sentido. O mérito profissional, a adesão a um objetivo transparente de gestão do conhecimento, podem impor-se como referência comum a todos os envolvidos, em lugar das lógicas particularsticas imanentes aos grupos políticos existentes, ciosos de guardar a sete chaves seus conhecimentos, tanto do público interno quanto externo.

O panorama que se desenha, assim, acena para a possibilidade de explicitação, consensualização e protocolização dos saberes e conhecimentos sobre a universidade, tornando os mesmos disponíveis para os processos de capacitação e qualificação profissional, seja em termos formais ou informais. Esboça-se um desenho institucional, portanto, no qual se expande para distintos segmentos técnico-administrativos a possibilidade de ascensão pessoal e profissional, mediante o possível interesse na internalização de normas e procedimentos que, uma vez públicos, tendem a servir de base para a reafirmação da vocação e, sobretudo, do mérito. Em outras palavras, buscar-se-á interferir, ou seja, ferir por dentro, a dimensão do segredo, do sigilo, assim comprometendo as estruturas - materiais e cognitivas que fazem dos métodos inquisitoriais a base de sustentação de uma hierarquia desigualadora, que se interpõe entre os segmentos universitários, como também entre a Universidade e a sociedade.

Os efeitos sobre os processos de escolha dos dirigentes institucionais, sejam aqueles voltados para eventuais reformas em uma equipe que detém certo mandato, sejam no tocante a renovação dos quadros dirigentes através dos mecanismos de sucessão, parecem-nos, assim, evidentes. A inversão da lógica vigente poderá fazer com que os interesses dos grupamentos legítimos em sua constituição - se submetam à gramática do mérito, corroborado por referenciais públicos de avaliação. Seu reconhecimento, assim, deverá ter por base protocolos de comportamento institucional e profissional, de domínio universal. As características subjetivas, assim, passariam a luzir como complemento do perfil desejado pela coletividade. Coletividade a qual, por sua vez, passa a incorporar também as demandas e aspirações de um público mais amplo, uma vez que sua produção estará alicerçada em metodologias de consulta a esse imaginário. 


\section{BIBLIOGRAFIA}

AMORIM, M. S. KANT DE LIMA, R., MENDES, R.L.T. Introdução. In Ensaios sobre a igualdade jurídica - Introdução. RJ: Editora Lumen Juris, xi-xxxvi. 2005.

CARDOSO DE OLIVEIRA, Luis Roberto. Direito Legal e Insulto Moral - Dilemas da Cidadania no Brasil, Quebec e EUA. Rio de Janeiro: Relume-Dumará. 2002

CARVALHO, José Murilo de. Cidadania no Brasil; o longo caminho. Rio de Janeiro: Civilização Brasileira. 2001

DA MATTA, Roberto - Carnavais, Malandros e Heróis. Rio: Editora Rocco. 1997

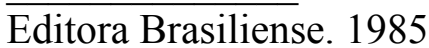

. A casa \& a rua - Espaço, cidadania, mulher e morte no Brasil. São Paulo;

DAVIS, Shelton (Org). Antropologia Jurídica - Estudo Comparativo de Categorias de Dívida e Contrato. Rio de Janeiro: Zahar Editores. P. 9-24. 1973

DUMONT, Louis. O individualismo. Uma perspectiva antropológica da ideologia moderna. Rio de Janeiro: Rocco. 2000.

FONSECA, João Eduardo do Nascimento. Novos atores na cena universitária. Rio de Janeiro: UFRJ/NAU. 1996

FOUCAULT, Michel. Vigiar e Punir. Petrópolis: Vozes. 2004

. A verdade e as formas jurídicas. Rio de Janeiro: NAU Editora. 2001

GEERTZ, C. A interpretação das culturas. Rio de janeiro: Editora Zahar. 1978

KANT DE LIMA, Roberto. A Polícia da cidade do Rio de Janeiro - seus dilemas e paradoxos. Rio de Janeiro: Editora Forense. 1995

. Antropologia da Academia: quando os índios somos nós. Niterói: Eduff.

1997

Carnaval, malandros e heróis: o dilema brasileiro do espaço público. In GOMES, Laura Graziela, BARBOSA, Lívia, DRUMOND, José Augusto (Orgs). O Brasil não é para principiantes. Rio de Janeiro: FGV, p. 105-123. 2000.

Policia, Justiça e Sociedade no Brasil: Uma abordagem comparativa dos Modelos de Administração de Conflitos no Espaço Público In Ensaios de Antropologia e de Direito. Autor: Roberto Kant de Lima. RJ: Ed. Lumen Júris. 2008.

, PIRES, Lenin \& ELBAUM, Lucía. Constituição e Segurança Pública:

exercício de direitos, construção de verdade e a administração de conflitos. In A Constituição 
de 1988 na vida brasileira. Ruben George Oliven, Marcelo Ridenti \& Gildo Marçal Brandão (orgs). São Paulo: Aderaldo \& Rothschild: Anpocs 152-190. 2008.

LOBÃO, Ronaldo J.S. Servidor Público: a serviço do Estado ou a serviço do público? Monografia de conclusão do curso de Ciências Sociais da Universidade Federal Fluminense. Mimeo. 1998.

MARSHALL, H. T. Cidadania, Classe Social e Status. Rio de Janeiro: Jorge Zahar Editor. 1965.

MOORE, Sally Falk. Law as a process. London, Henley and Boston. 1978

SANTOS, Wanderley G. dos. Do laissez faire repressivo à cidadania em recesso. In Cidadania e Justiça. Rio de Janeiro: Ed. Campus. 1979

TEXEIRA MENDES, R. Igualdade à brasileira: cidadania como instituto jurídico no Brasil. Em: AMORIM, Maria Stella de ; LIMA, Roberto Kant de ; MENDES, Lúcia Teixeira (Org.). Ensaios sobre a igualdade jurídica: acesso à justiça criminal e direitos da cidadania no Brasil. Rio de Janeiro: Lumen Juris,. p.1-33. 2005.

WEBER, Max. Os fundamentos da organização burocrática: uma construção do tipo ideal. In Sociologia da Burocracia. Edmundo Campos (org). RJ: Zahar editores. 15-28. 1978. 